\title{
A comparison between skinfold callipers and ultrasound imaging for assessing body composition in recreationally active students
}

Kim Nolte

Reon A Van der Merwe

Cindy A Helena

Biokinetics and Sport Science, Department of Physiology, University of Pretoria

Pretoria, South Africa

kim.nolte@up.ac.za
Heinrich W Nolte

Julia van der Meulen
ERGOnomics TECHnologies, Research and Development, Armscor SOC Ltd

Centurion, South Africa

heinrich@ergotech.co.za julie@ergotech.co.za

http://dx.doi.org/10.4314/esa.v28i1.3

\begin{abstract}
The measurement of skinfold thickness by means of skinfold callipers (SC) is a widely accepted method to assess subcutaneous fat thickness and percentage body fat $(\% \mathrm{BF})$. Ultrasound imaging (USI) is a more recent technology that is becoming accessible for the same application. The objective of this study was to compare measurements recorded by SC and USI for the assessment of subcutaneous fat thickness in order to estimate \%BF. Thirty adults volunteered for the study. Body mass, stature and subcutaneous fat thickness for seven sites were measured. Strong $(\mathrm{p}<0.01)$ correlations were found between SC and USI measurements for all the sites except for the abdomen. Despite significant $(\mathrm{p}<0.05)$ differences for fat thickness of all sites, there was no significant $(\mathrm{p}>0.05)$ difference between the $\% \mathrm{BF}$ determined by the two methods $(\mathrm{SC}=19.5 \pm 6.4 \% \mathrm{BF}$ and USI $=19.0 \pm 6.3 \% \mathrm{BF})$. However, levels of agreement indicated that the USI could over- or underestimate $\% \mathrm{BF}$ by $\pm 10 \%$. This resulted in $\% \mathrm{BF}$ estimation errors which are deemed too large from a clinical perspective. Additional studies are recommended to investigate the lack of agreement and bias highlighted between the two methods.
\end{abstract}

Keywords: Percentage body fat, field assessments, subcutaneous fat thickness.

\section{Introduction}

The assessment of body composition is useful in the sport, health and wellness industries (Ryder and Ball, 2012). Body composition, particularly percentage body fat $(\% \mathrm{BF})$ can be measured in several ways. In particular, two field methods that are currently available to determine skinfold thickness and subsequent subcutaneous fat thickness include the use of skinfold callipers (SC) and ultrasound imaging (USI). Although there are reviews detailing the various methods (including SC) for assessing 
body composition, Wagner (2013) highlights that less is known about USI as a suitable body composition assessment method.

Skinfold thickness measured with SC has been used for many years to assess subcutaneous fat thickness and percentage body fat $(\% \mathrm{BF})$, and according to Beechy et al. (2012) its popularity has been fuelled by its low cost and relative simplicity in method and feasibility. Quantifying body composition by means of skinfold measurements attempt to make an assumption, using subcutaneous body fat measurements to estimate total body fat (Sabir et al. 2001), yet the validity of skinfold measurements can be affected by numerous variables. Measuring skinfold thickness requires meticulous technique using a SC and the skillfulness of the measurer will influence the result (Jackson and Pollock, 1985). Furthermore, accurate measurement might be difficult to attain in all individuals, especially in those with adipose tissue that does not separate well from the underlying muscle or when the end range of the SC is too small to capture the entire subcutaneous fat thickness. Inter-rater reproducibility of measurements using SC is not high, resulting in clinicians questioning the accuracy of the measurement (Selkow et al. 2011). These limitations have led researchers to find and implement techniques which are less time consuming and easier for the measurer to conduct (Cable et al. 2003).

While USI has existed for several decades, it is only due to recent advances in technology that it is becoming more accessible for the measurement of subcutaneous fat thickness in order to estimate \%BF. USI has been previously classified as a laboratory method but due to improvements in size and portability, USI has developed into a viable field method (Wagner, 2013). Most scientists are familiar with the biomedical diagnostic application of USI but less is known about the use of USI to measure fat and muscle thicknesses in humans (Wagner, 2013). USI makes use of a single beam sonic wave, which uses frequency as a means to produce quantitative data regarding the layers of tissue in the selected area. Ultrasound transducers vary with regard to mode and frequency. An A-mode, or amplitude mode, transducer relies on a narrow beam to scan tissue discontinuity and produces a spike on a graph. B-mode, or brightness modulation, scanning uses a linear array to produce a two-dimensional image by combining A-mode signals from various detections (Noce, 1990). Unlike SC which measure fold thickness, USI measures tissue thickness (Heyward and Wagner, 2004). Unfortunately, there are no universally accepted guidelines for measuring subcutaneous adipose tissue with USI (Wagner, 2013). Although USI is more expensive than other field body composition devices, it may offer several advantages such as a smaller margin of technical limitations with respect to different body types and is not limited by subcutaneous fat thickness, loose connective tissue, or hydration status (Heyward and Wagner, 2004; Pereira et al. 2012; Semiz et al. 2007). In addition, unlike SC, USI does not require having to grasp any specific folds, and subsequently without tissue compression possibly eliminating a certain frame of error (Fanelli and Kuczmarski, 1984).

There are limited studies that have compared SC and USI measurements recorded at various anatomical locations, and the strength of correlation between the two methods varies considerably by site and gender (Fanelli and Kuczmarski, 1984; Borkan et al. 1982). Due to the limited research and varied results using a portable hand-held 2.5 $\mathrm{MHz}$ A-mode ultrasound transducer, specifically for the purpose of body composition assessment, further validity and reliability studies have been recommended (Ulbricht et 
al. 2012). Therefore, the objective of this study was to compare measurements from SC with USI (using the BodyMetric BX2000) in assessing subcutaneous fat thickness for seven sites and overall \%BF. It was hypothesized that there would be a strong correlation and acceptable level of agreement between the measurements using the two techniques.

\section{Method}

\subsection{Experimental approach to the problem}

A correlational design was used for this study in which all subjects were measured using both SC and USI. This approach was adopted in order to compare measurements from SC with USI in assessing subcutaneous fat thickness for seven sites and overall \%BF.

\subsection{Subjects}

Recreationally active students from the University of Pretoria (South Africa) were recruited and asked to volunteer for the study. Subjects were briefed on the study purpose and procedures before giving written informed consent. Ethical clearance for this study was obtained from the research proposal and ethics committee of the Department of Biokinetics, Sport and Leisure Science, University of Pretoria, South Africa.

\subsection{Procedures}

Stature and body mass was measured and recorded, using a SECA calibrated scale and stadiometer (Seca GmbH \& Co. KG, Hamburg). Stature was recorded to the nearest 1 $\mathrm{mm}$, and body mass to the nearest $0.1 \mathrm{~kg}$. Each subject was assessed on the same day by two measurers. Both measurers (International Society for the Advancement in Kinanthropometry (ISAK) level 1 accredited) determined the subcutaneous fat thickness at seven sites (Jackson and Pollock) using SC and USI (Semiz et al. 2007). The seven sites included the abdominal, chest, thigh, triceps, subscapular, supra-iliac and midaxillary (Semiz et al. 2007). Land-marking was carried out in accordance with the guidelines stipulated by the ISAK. The same landmark sites were used for both the SC and USI measurements.

A Harpenden SC (Baty International, West Sussex) and the HosandBodyMetrixTM BX2000 Ultrasound system (BodyMetrix, California) were used to measure the sites. The Harpenden SC was selected for its high accuracy (Kisert and Merrifield, 1987). The BodyMetrix USI device is an A-mode ultrasound device, with a single beam. All equipment was calibrated according to manufacturer specifications prior to the collection of any data.

\subsubsection{Skinfold calliper measurements}

Each skinfold was measured twice, and the average of the two measurements was used in subsequent calculations. A third measurement was performed when the first two measurements differed by more than $1.0 \mathrm{~mm}$. The skinfold measurements were performed in succession, in order to prevent unnecessary compression of the subcutaneous adipose tissue. The final value for each skinfold was recorded as the average thickness as determined by the two measurers. SC measurements are based on a double layer of subcutaneous fat, measuring the width in $\mathrm{mm}$. Therefore, in order to 
obtain a reasonable estimate (Otte et al, 2002) of the fat thickness recorded by the SC compared with the USI it was divided in half to represent the subcutaneous fat layer over the muscle (Selkow et al. 2011; Ulbricht et al. 2012). This method is also used when thermocouples are inserted to evaluate temperature changes in various depths of tissue; for this application subcutaneous tissue thickness is assessed by using SC and dividing the measurement in half. While thus far this method has not been challenged for accuracy (Otte et al. 2002; Merrick et al. 2003; Draper et al. 1995), it must be noted that a direct comparison of subcutaneous fat as measured by SC and USI would not be a prudent approach. Inherent measurement uncertainty exists for the SC method due to compressibility and viscoelasticity of adipose tissue as well variation in individual skin thicknesses (Ramirez, 1992; Moore et al, 2003). However the value in correcting SC measures for these variables is limited due to heterogeneity in fold compression at various sites and among individuals and also due to variance in skin thickness between sites (Müller et al, 2013; Himes et al, 1979). This was only performed in order to obtain a reasonable estimate for comparison of the thickness as measured by the different techniques at the individual sites and not for the calculation of the sum of the skinfolds for the seven sites or the determination of the \%BF. The Jackson and Pollock equation was used to determine the body density and those results in turn were used as inputs to the Siri equation to determine the \% BF of the subjects for the $\mathrm{SC}$ measurements.

\subsubsection{Ultrasound imaging measurements}

The USI method required the use of an ultrasound-gel, applied to the surface of the skin, on and around the skinfold site, to act as a medium for the ultrasound waves. The USI device was applied perpendicularly to the surface of the skin, with a minimum amount of pressure. The device was moved over the respective landmark and held in a stationary position while the recording was performed. Two recordings of each site, taken in succession, were recorded. The final value for each site was recorded as the average thickness as determined by the two measurers. The USI device measures depth of subcutaneous fat in mm. The USI software BodyView, considers that the interfaces between the layers, body fat-muscle and muscle-bone have distinct coefficients of reflection $(\mathrm{R}), \mathrm{R}=0.012$ and $\mathrm{R}=0.22$ respectively. It allows the estimation of these layers (Silva, 2010). The software furthermore allows for the selection of either "elite", "athletic" or "non-athletic" as a descriptor for the participant being evaluated. Changes in this setting will influence the identification of the peak that represents the fat-muscle junction. The "athletic" setting was chosen for our study as all our participants were recreationally active. The measure of the fat layer is given by the ultrasonic differences of characteristics of fat, muscles and bones such as density $\left(\mathrm{kg} / \mathrm{m}^{3}\right)$, impedance $\left(\mathrm{kg} / \mathrm{m}^{2} \mathrm{~s}\right)$ and attenuation coefficient $(\mathrm{dB} / \mathrm{cm})$ (Ulbricht et al. 2012).

\subsection{Statistical Analysis}

The statistical analysis of the data was conducted using the Statistica software package. Relevant descriptive and regression analyses were performed; the Pearson Product Correlation Coefficient and the Wilcoxon Signed Rank test was used to determine whether or not there was a statistically significant correlation and/or differences $(p<0.05)$ between the USI and SC measurements respectively. The correlations between results obtained by both tools were determined for the individual site subcutaneous fat thickness measurements and the overall \%BF. For the purpose of this study an $r$ - value of $0.20-0.39$, was classified as a weak relationship, an $r$ - value of $0.40-0.69$ was 
classified as a moderate relationship, and an $r$ - value of $0.70-0.90$ was described as being a strong relationship (Heyward, 2010). The use of correlation coefficients (r) only might, however, not provide a reliable estimate of agreement between two measurement techniques. Bland and Altman (1986) states that while $r$ - values measure the strength of relationships it does not provide insight into the agreement between the methods. A perfect correlation occurs if data points lie along a straight line, however perfect agreement occurs if data points lie along a line of equality. Therefore correlation statistics should not be reported in isolation because it does not consider the potential bias between two methods of assessment. Agreement between USI and SC was therefore visually assessed by scatter plots with lines of equality and determined by Bland-Altman plots. Validity and lack of agreement between the USI and SC methods was assessed by determining the difference between the methods and standard deviations (SD) of the differences. The 95\% limits of agreement (LoA) (inter method difference $\pm 1.96 \mathrm{SD}$ ) were also calculated.

\section{Results}

Thirty students (17 males and 13 females) from the University of Pretoria (South Africa) volunteered to take part in the study. The mean $( \pm \mathrm{SD})$ age, body mass, stature and body mass index (BMI) of the subjects was $21.5 \pm 1.76$ years, $69.4 \pm 14.5 \mathrm{~kg}, 171 \pm$ $9.3 \mathrm{~cm}$ and $23.63 \pm 2.9$ respectively.

Table 1 demonstrates the comparison of the USI and SC methods used to determine subcutaneous fat thickness $(\mathrm{mm})$ and \%BF measurements in terms of specific skinfold sites, sum of skinfolds and total \%BF. There were strong ( $\mathrm{r}$ ranging from 0.70 to 0.95 ) and statistically significant $(\mathrm{p}<0.05)$ correlations between the two devices for the measurements of all the skinfold sites except for the abdominal site $(r=-0.06, p>0.05)$. Irrespective of these relationships, however, results indicate statistically significant $(p<0.05)$ differences between the USI and the SC subcutaneous fat thickness measurements for all seven sites measured. This did not impact the \% BF as determined by both the USI and SC methods as there was no statistically significant difference $(\mathrm{p}>0.05)$ and a strong $(\mathrm{r}=0.70)$ and significant $(\mathrm{p}<0.01)$ correlation between the estimated \%BF values obtained using both techniques (Table 1). 
Table 1. Comparison of subcutaneous fat thickness ( $\mathrm{mm})$ and percentage body fat as determined by the ultrasound imaging (USI) and the skinfold calliper (SC) methods. Note: SC values presented below were calculated by dividing the actual skinfold thickness measured by half.

\begin{tabular}{|c|c|c|c|}
\hline Measurement & $\begin{array}{c}\text { Mean } \pm \text { SD } \\
(\mathrm{mm})\end{array}$ & $\begin{array}{c}\text { PCC } \\
\text { (r value) }\end{array}$ & Mean Bias $\pm 95 \%$ LoA \\
\hline $\begin{array}{r}\text { Triceps }^{\#} \\
\text { SC } \\
\text { USI }\end{array}$ & $\begin{array}{l}6.2 \pm 3.0 \\
8.1 \pm 4.1\end{array}$ & $0.95 *$ & $-1.86 \pm 3.8$ \\
\hline $\begin{array}{r}\text { Scapula }^{\#} \\
\text { SC } \\
\text { USI }\end{array}$ & $\begin{array}{l}5.3 \pm 1.7 \\
6.0 \pm 1.9\end{array}$ & $0.80 *$ & $-0.75 \pm 2.26$ \\
\hline $\begin{array}{r}\text { Chest }^{\#} \\
\text { SC } \\
\text { USI }\end{array}$ & $\begin{array}{l}3.4 \pm 1.4 \\
6.8 \pm 3.6\end{array}$ & $0.78 *$ & $-3.37 \pm 5.64$ \\
\hline $\begin{array}{r}\text { Abdominal }^{\#} \\
\text { SC } \\
\text { USI }\end{array}$ & $\begin{array}{c}9.0 \pm 3.8 \\
20.3 \pm 7.3\end{array}$ & -0.06 & $-11.24 \pm 15.34$ \\
\hline $\begin{array}{r}\text { Supra-iliac }^{\#} \\
\text { SC } \\
\text { USI }\end{array}$ & $\begin{array}{c}8.7 \pm 4.1 \\
10.4 \pm 3.4\end{array}$ & $0.70 *$ & $-1.69 \pm 6.84$ \\
\hline $\begin{array}{c}\text { Mid-axillary }^{\#} \\
\text { SC } \\
\text { USI }\end{array}$ & $\begin{array}{c}8.2 \pm 3.9 \\
10.1 \pm 4.3\end{array}$ & $0.77 *$ & $-1.92 \pm 5.50$ \\
\hline $\begin{array}{l}\text { Thigh }^{\#} \\
\text { SC } \\
\text { USI }\end{array}$ & $\begin{array}{c}10.0 \pm 4.7 \\
7.9 \pm 3.3\end{array}$ & $0.76^{*}$ & $2.05 \pm 5.86$ \\
\hline $\begin{array}{c}\text { Sum of Skinfolds }{ }^{\#} \\
\text { SC } \\
\text { USI }\end{array}$ & $\begin{array}{c}51.1 \pm 20.4 \\
69.9 \pm 3.3\end{array}$ & $0.84 *$ & $-18.8 \pm 28.58$ \\
\hline $\begin{array}{r}\text { Total BF \% } \\
\text { SC } \\
\text { USI }\end{array}$ & $\begin{array}{l}19.5 \pm 6.4 \\
19.0 \pm 6.3\end{array}$ & $0.70^{*}$ & $0.52 \pm 10.16$ \\
\hline
\end{tabular}

LoA $=$ Limits of Agreement, $\mathrm{PCC}=$ Pearson Product Correlation Coefficient, ${ }^{*}=$ $\mathrm{p}<0.05,{ }^{\#}=$ indicate a significant $(\mathrm{p}<0.05)$ difference between subcutaneous fat thickness as determined by the SC and USI methods

In addition to the correlations identified, further interpretation of the data in terms of agreement limits between the two techniques was performed. The scatter plots with lines of equality (Figure $1[\mathrm{a}-\mathrm{h}]$ ) illustrate the agreement between SC and USI for each skinfold site as well as the sum of the skinfolds. From Figure 1, it is evident that there is considerable lack of agreement between the skinfold thickness as determined by the two methods for all skinfold sites as well as the sum of skinfold sites. This finding is not unexpected considering the influence of compressibility and viscoelasticity of adipose tissue as well variation in individual skin thicknesses across measurement sites. For all skinfold sites except the thigh site (Figure $1[\mathrm{~g}]$ ), the majority of the data points are plotted to the left of the line of equality; indicating a bias such that the USI measured thicker subcutaneous fat compared to the SC. The mean bias (Table 1) was therefore negative for all the skinfold sites except for the thigh. 


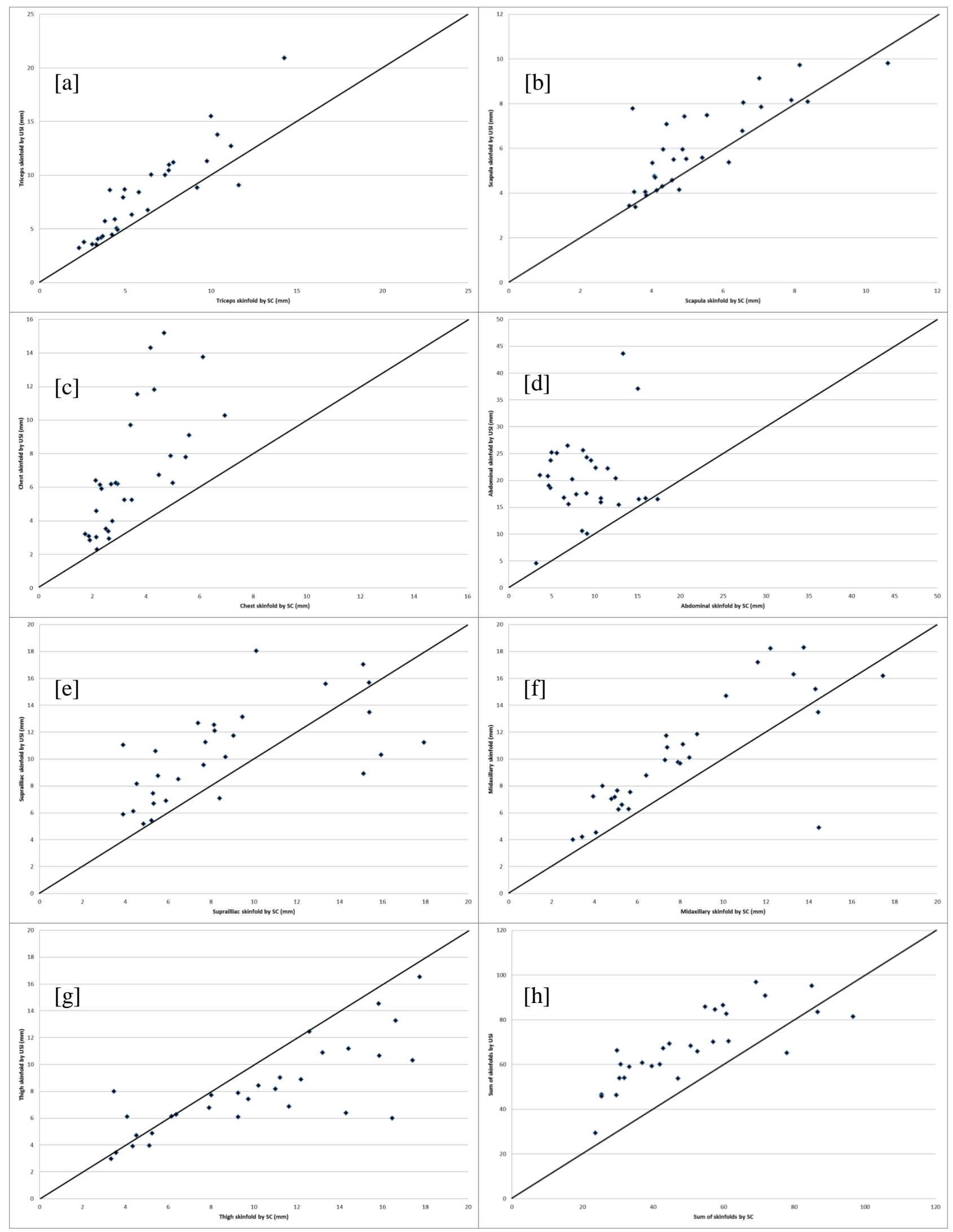

Figure 1 [a] - [h]. Scatter plots with line of equality for subcutaneous fat thickness as determined by the ultrasound imaging (USI) and the skinfold calliper (SC) methods) 
Figure 2 presents a scatter plot with line of equality between $\% \mathrm{BF}$ as determined by the SC and USI methods. Considering the mean bias (Table 1), LoA and visual comparison with Figure $1([\mathrm{a}]-[\mathrm{g}])$, it is clear that while the agreement between the two methods are low at the specific skinfold measurement sites, there was not a distinct bias towards the USI recording a higher percentage body fat.

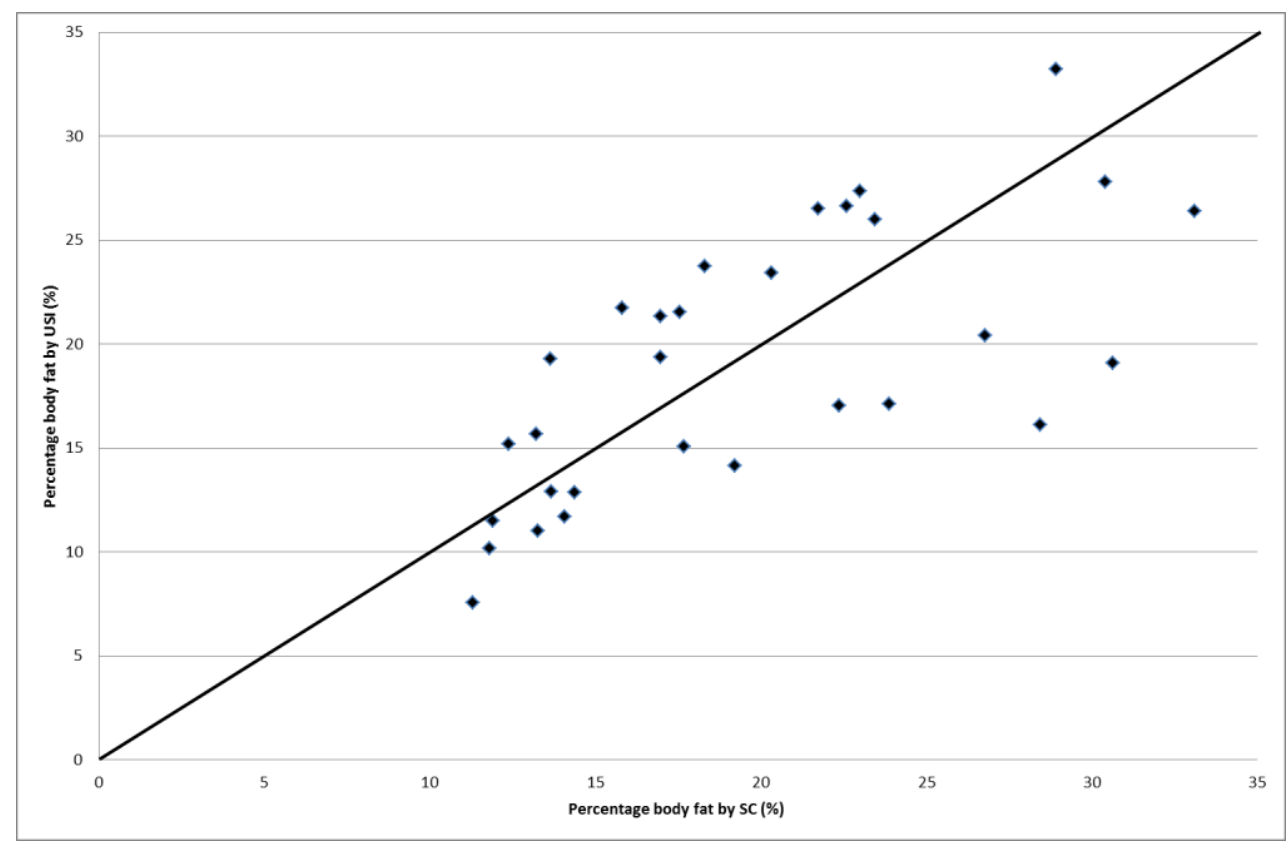

Figure 2. Scatter plots of percentage body fat as determined by the ultrasound imaging (USI) and the skinfold calliper (SC) methods with line of equality

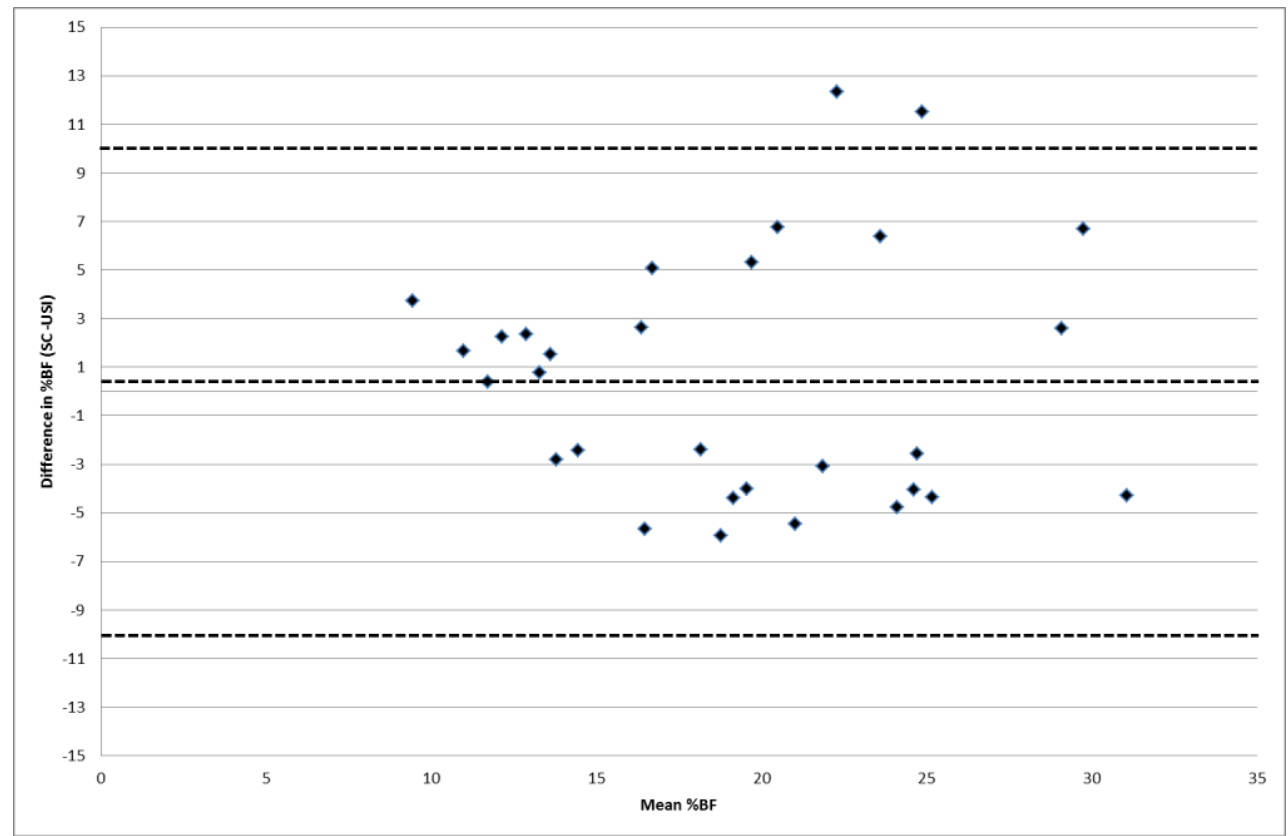

Figure 3. Differences against mean for percentage body fat 
Figure 3 presents the mean difference in $\% \mathrm{BF}$ by the two methods plotted against the overall average percentage body fat as determined by the two methods. The mean difference $(0.52)$ and the LoA $( \pm 10.16)$ are indicated by the dashed lines in Figure 3.

\section{Discussion}

The first relevant finding is that there were strong and significant correlations between the subcutaneous fat thickness as determined by the SC and USI for all sites except the abdominal site (Table 1). These results are supported by those of Selkow et al. (2011) who compared SC and USI at four sites on the thigh and found a strong correlation between the two methods $(\mathrm{r}=0.90, \mathrm{p}<0.001)$ specifically in leaner individuals. Ulbricht et al. (2012) also observed correlations at the thigh site, measured on a group of 30 overweight $\left(\mathrm{BMI}>25 \mathrm{~kg} / \mathrm{m}^{2}\right)$ and 30 normal weight Brazilian military subjects. The postulated reasoning for these results was the lower fat thickness and greater muscular development in this body region since various other anatomical sites measured by Ulbricht et al. (2012) resulted in weak and non-significant correlations.

It is considered that the site of measurement influences the strength of the correlation. In this study the correlations ( $r$ ) varied from 0.70 to 0.95 (excluding the abdominal site), with the triceps and scapula sites showing the strongest correlations. The structure or anatomy of the body region, therefore, could influence the SC and USI measurements and therefore, influence the correlations. This could possibly explain the poor correlation for the abdominal site in this study. In addition, Gray et al. (1990) highlights that the abdomen is often an area with a substantial amount of subcutaneous fat in comparison to other sites allowing for an increased opportunity for measurement error. Furthermore, the distances between the fat-muscle and bone-muscle interfaces which are considered important reference points with regards to the USI measurements could also have influenced the correlation (Ulbricht et al. 2012). Other possible contributing factors include incorrect technique when either measuring the site with the SC or the USI, improper land-marking of the abdominal site or a wrong classification of the participants using the software. As all our participants were recreationally active we selected the "athlete" setting prior to performing the measurement. As this setting alters the manner in which the fat-muscle junction is identified it is important to ensure the best possible fit between the setting and the participant being assessed.

The second relevant finding is that there was a significant and strong correlation $(\mathrm{r}=0.70, \mathrm{p}<0.01$,$) and no significant difference (\mathrm{p}>0.05)$ between the \%BF estimations using both tools $(\mathrm{SC}=19.5 \pm 6.4 \% \mathrm{BF}$ and $\mathrm{USI}=19.0 \pm 6.3 \% \mathrm{BF})$. Similar results were reported by both Lyon et al. (2006) and Ulbricht et al. (2012). Lyon and colleagues reported suitable agreement between the estimate of \%BF for women (SC=18.7\% \pm 3.6 $\% \mathrm{BF}$; USI $=18.4 \% \pm 3.7 \% \mathrm{BF}$ ) and men (SC=10.7 $\pm 4.2 \% \mathrm{BF}$; USI $=10.2 \pm 3.9 \% \mathrm{BF})$ in young lean athletic males and females. It is interesting to note that while our results indicate a strong correlation and non-significant difference for estimation of $\% \mathrm{BF}$, all the individual subcutaneous fat measurements reflected statistically significant $(p<0.05)$ differences when comparing the results obtained by the two methods. This finding is not unexpected considering the influence of compressibility and viscoelasticity of adipose tissue as well variation in individual skin thicknesses across measurement sites. Contrary to our findings, Ulbricht et al. (2010) reported weak, non-significant 
correlations between SC and USI for most of the anatomical locations as previously mentioned, however their results agreed with this study by showing strong agreement and no significant difference in the \%BF estimated from SC $(13.25 \pm 6.32 \%)$ and USI $(12.73 \pm 5.95 \%)$. Furthermore, the $\% \mathrm{BF}$ values determined in the current study using the USI were slightly lower in comparison to the SC which are in accordance to those of Ulbricht et al. (2012) and Lyon et al. (2006).

The most important finding of the study was highlighted by the statistical techniques utilised to analyse the data. At first glance the strong and significant correlations between the individual skinfold sites and the lack of any significant difference in the estimated \% BF might suggest that these two methods could be used interchangeably as a method to assess body composition in our population. The use of scatter plots with lines of equality and Bland-Altman plots, however, clearly indicate the lack of agreement between the two methods. The agreement between the methods varied considerably depending on the location of measurement with the scapula and the abdominal skinfold site producing the smallest and largest LoA respectively. For all skinfold sites except the thigh, the bias was negative, implying that the USI measured thicker subcutaneous fat thickness when compared to the SC. This was in contrast to Selkow et al. (2011) who compared SC and USI at four sites on the thigh. They found a strong correlation between the two $(r=0.90, p<0.001)$ methods in leaner individuals, but the SC tended to overestimate the thickness in individuals with higher fat values. Mean differences between measures ranged from $1.7 \pm 2.6 \mathrm{~mm}$ (distal rectus femoris) to $3.7 \pm 2.6 \mathrm{~mm}$ (proximal rectus femoris) (Selkow et al. 2011).

With regards to $\% \mathrm{BF}, 28$ out of $30(93 \%)$ of the data points were distributed within the 95\% LoA. Although this might suggest high statistical validity of the use of the two methods to determine $\% \mathrm{BF}$, the LoA is too large to provide acceptable results from a clinical perspective. Thus the USI may provide percentage body fat values $10 \%$ higher or lower compared to the SC method, contradicting the original impressions given by the strong and statistically significant correlations, as well as the non-significant differences between the $\% \mathrm{BF}$ measurements. This finding highlights the possible limitations of statistical methods that only consider correlations and differences between the means of data sets.

Additional studies are recommended in order to investigate the lack of agreement and bias highlighted between the two methods; these might prove valuable in evaluating the use of USI as alternative to SC. Future studies should take the following limitations of our study into account: Firstly, the sample is relatively small and should be increased. A sample with a greater variation in body compositions might be valuable in highlighting possible limitations and strengths of the USI technique compared to SC and other methods. It is also noted that while the measurers in this study had ample time to familiarize themselves with the USI technique, they had more experience and practice using SC. It is therefore critical that when using both tools the measurers have undergone the appropriate training, have adequate experience and practice in taking the measurements and follow the correct procedures to ensure accurate and reliable results. Lastly, the USI method should be compared to a more reliable gold standard for assessing body composition, ideally a method such as dual-energy X-ray absorptiometry. Additional studies are furthermore warranted by anecdotal evidence provided by both the subjects and the measurers who favoured the USI over the SC. 
The subjects indicated that they preferred the USI, as it was less invasive and felt more comfortable. The measurers in turn commented on the computing system and programme of the USI device that allowed automatic recording of measurements, immediate results of $\% \mathrm{BF}$, client profiling and additional valuable feedback reports for both the practitioner or measurer and the participant.

\section{Conclusion}

Results from this study indicate strong correlations between the two tools at the anatomical sites as well as \%BF implying that USI and SC would produce similar results regarding subcutaneous fat thickness and estimated \%BF. However, further analysis indicate the agreement between the two methods were indeed unacceptable from a clinical perspective. It is still supposed that USI may be a practical alternative to SC or traditional anthropometric measurements for the assessment of body composition but several limitations of this study need to be addressed for verification purposes.

\section{References}

Beechy, L., Galpem, J., Petrone, A., \& Das, S.K. (2012). Assessment tools in obesitypsychological measures, diet, activity and body composition. Physiol and Behav, 107(4): 154-71.

Bland, J.M., \& Altman, D.G. (1986). Statistical methods for assessing agreement between two methods of clinical measurement. Lancet, 1: 307-310.

Borkan, G.A., Hults D.E., Cardarelli J., \& Burrows B.A. (1982). Comparison of ultrasound and skinfold measurements in assessment of subcutaneous and total fatness. Am J Phys Anthropol, 58(3): 307-313.

Cable, A., Nieman, D.C., Austin, M., Hozen, E., \& Utter, A.C. (2003). Validity of the leg-to-leg bioelectrical impedance measurements in males. J Sports Med Phys. Fitness, 37(3): 278-279.

Draper, D.O., Schulthies, S., Sorvisto, P., \& Hautala, A.M. (1995). Temperature changes in deep muscles of humans during ice and ultrasound therapies: an in vivo study. J Orthop Sports Phys Ther, 21(3): 153-157.

Fanelli, M.T., \& Kuczmarski, R.J. (1984). Ultrasound as an approach to assessing body composition. Am J Clin Nutr, 39(1): 703-9.

Gray, D.S., Bray, G.A., Bauer, M., Kaplan, K., Gemayel, N. \& Wood, R. (1990). Skinfold thickness measurements in obese subjects. Am J Clin Nutr, 51: 571-7.

Heyward, V.H. (2010). Advanced fitness assessment and exercise prescription. Champaign, IL: Human Kinetics.

Heyward, V.H., \& Wagner, D.R. (2004). Applied body composition assessment. Champaign, IL: Human Kinetics. 
Himes, J.H., Roche, A.F., \& Siervogel, R.M. (1979). Compressibility of skinfolds and the measurement of subcutaneous fatness. Am J Clin Nutr, 32: 1734-1740.

Jackson, A.S. \& Pollock, M.L. (1985). Practical assessment of body composition. Physician and Sportsmedicine, 13(5): 76-90.

Kisert, C.P., \& Merrifield, H.H. (1987). Interrater reliability of skinfold fat measurements, J Am Phys Ther Assoc, 67(6): 917-20.

Lyon, J., Drew, R., \& MacRae, H. (2006). Comparison of skinfold thickness measures with ultrasound imaging to determine body composition, Proceedings of the 26th Annual Meeting of the Southwest Chapter of the American College of Sports Medicine, San Diego, Calif, USA.

Merrick, M.A., Jutte, L.S. \& Smith, M.E. (2003). Cold modalities with different thermodynamic properties produce different surface and intermuscular temperatures, $J$ Athl Train, 38(1): 28-33.

Moore, T.L. Lunt, M., McManus B, et al. (2003). Seventeen-point dermal ultrasound scoring system - a reliable measure of skin thickness in patients with systemic sclerosis, Rheumatology, 42: 1559-1563.

Muller, W., Horn, M., Furhapter-Rieger, A., Kainz, P., Kropfl, J.M., Maughan, R.J., \& Ahammer, H. (2013). Body composition in sport: a comparison of a novel ultrasound imaging technique to measure subcutaneous fat tissue compared with skinfold measurement, Br J Sports Med, 47: 1028-1035.

Noce, J.P. (1990). Fundamentals of diagnostic ultrasonography, Biomed Instrum Techn, 24(6): 456-459.

Otte, J.W., Merrick, M.A., Ingersoll, C.D., \& Cardosa, M.L. (2002). Subcutaneous adipose tissue thickness alters cooling time during cryotherapy, Arch Phys Med Rehab, 83(11): 1501-1505.

Pereira, A.Z., Marchini, J.S., Carneiro, G., Arasaki, C.H., \& Zanella, M.T. (2012). Lean and fat mass loss in obese patients before and after Roux-en-Y gastric bypass: A new application for ultrasound technique, Obes Surg J, 22(1): 597-601.

Ramirez, M.E. (1992). Measurement of subcutaneous adipose tissue using ultrasound images, Am J Clin Nutr, 89: 347-357.

Ryder, J.R., \& Ball, S.D. (2012). Three-dimensional body scanning as a novel technique for body composition assessment, J Exerc Physiol, 15(1): 1-14.

Sabir, N., Sermez, Y., Kazil, S., \& Zencir, M. (2001). Correlation of abdominal fat accumulation and liver steatosis: importance of ultrasonographic and anthropometric measurements, Eur J Ultrasound, 14(1): 121-8. 
Selkow, N.M., Pietrosimone, B.G., \& Saliba, S.A. (2011). Subcutaneous thigh fat assessment: A comparison of skinfold calipers and ultrasound imaging, $J$ Athl Train, 46(1): 50-4.

Semiz, S., Ozgoren, E., \& Sabir, N. (2007). Comparison of ultrasonographic and anthropometric methods to assess body fat in childhood obesity, Int J Obes, 31(1): 53-8.

Silva, L. (2010). An introduction to ultrasound and the Body Metrix System, ppt file, Intela Metric, $17 \mathrm{p}$.

Ulbricht, L., Neves, E.B., Ripka, W.L., \& Romaneli, E.F.R. (2012). Comparison between body fat measurements obtained by portable ultrasound and caliper in young adults. In Proceedings of the Annual International Conference of the IEEE Engineering in Medicine and Biology Society (EMBS '12), 1952-1955.

Wagner, D.R. (2013). Ultrasound as a tool to assess body fat. J Obes. Article ID 280713, 9 pages. 